\title{
Fitomassa epigéa da mata ciliar do rio Mogi-Guaçu, Itapira - SP
}

\author{
DÉBORAH MOREIRA-BURGER ${ }^{1}$ e WELINGTON B. C. DELITTI ${ }^{2,3}$
}

(recebido em 23/12/98; aceito em 22/09/99)

\begin{abstract}
Above ground plant biomass of the gallery forest at the Mogi-Guaçu river, Itapira - SP). The objective of this study is to determine the above ground plant biomass of the Mogi-Guaçu river gallery forest and to identity the best equation to predict the above ground tree biomass. This study was carried out in a remaining fragment of mesophyllous forest, located in Itapira, São Paulo ( $22^{\circ} 21^{\prime} \mathrm{S}$ and $\left.46^{\circ} 51^{\prime} \mathrm{W}\right)$. Twelve plots of $25 \mathrm{~m}^{2}$ were established to determine the above ground plant biomass by destructive method. Trees were identified and cut down at ground level. Each tree had its height and basal perimeter registered. Leaves and woody material were manually separated and the fresh weight for these two fractions was determined. Herbs and shrubs lower than $1.3 \mathrm{~m}$ height in a 3 $\mathrm{m}^{2}$ of each plot were cut down at ground level and fresh weight of the woody and non-woody fractions was also determined. The same procedure was used to evaluate the biomass of lianas. Samples of each fraction were dried at $80^{\circ} \mathrm{C}$ to constant weight the determine the dry weight. The total phytomass estimated for the forest was $133.3 \mathrm{t} / \mathrm{ha}$. The tree layer accounted for $88.5 \%$, and lianas and herbs for $11,3 \%$ and $0.2 \%$, respectively. The best equation to predict tree biomass in similar forests is: Total tree biomass $=[0.523+0.053$ perimeter] $]^{3}$.
\end{abstract}

RESUMO - (Fitomassa epigéa da mata ciliar do rio Mogi-Guaçu, Itapira - SP). Este trabalho teve como objetivos estimar a fitomassa epigéa da mata ciliar do rio Mogi-Guaçu e determinar a melhor equação preditiva da fitomassa arbórea. O trabalho foi realizado num fragmento de mata localizado no município de Itapira - SP (22 $21^{\prime} \mathrm{S}$ e $\left.46^{\circ} 51^{\prime} \mathrm{W}\right)$. Foram delimitadas 12 parcelas de $25 \mathrm{~m}^{2}$, para determinação da fitomassa através do método destrutivo. Os indivíduos arbóreos foram identificados e cortados ao nível do solo. De cada árvore, foram tomadas medidas de perímetro basal e altura. As folhas foram separadas manualmente dos ramos para determinação do peso fresco da porção foliar e lenhosa. A vegetação herbácea-arbustiva, de porte inferior a 1,3 m, existente em 3 m² de cada parcela, foi cortada ao nível do solo e tomadas as medidas de peso fresco da porção lenhosa e não lenhosa. O mesmo procedimento foi adotado para as lianas. Amostras de cada fração foram secas em estufa a $80^{\circ} \mathrm{C}$, até peso constante, para determinação do peso seco. A fitomassa média obtida foi de 133,3 t.ha $^{-1}$, sendo $88,5 \%$ referentes ao estrato arbóreo, $11,3 \%$ às lianas e $0,2 \%$ ao estrato herbáceo. A equação que melhor estima a fitomassa arbórea total de mata com características e condições semelhantes às da mata ciliar estudada foi definida como: Massa seca total $=[0,523+0,053 \text { perímetro }]^{3}$.

Key words - Allometry, biomass, gallery forest

\section{Introdução}

A biomassa constitui um dos aspectos mais importantes para a caracterização estrutural dos ecossistemas, pois expressa o potencial de acumulação de energia e nutrientes pela biota em interação com fatores ambientais. A biomassa presente a cada momento é a resultante das características genéticas de todas as espécies, dos fatores abióticos e da história de cada ecossistema. Desta forma, constitui-se em parâmetro relevante para a análise e monitoramento de todos os ecossistemas, bem como para avaliação de impactos, análise de estágios de sucessão e avaliação da capacidade de produção primária,

1. Companhia de Saneamento Básico do Estado de São Paulo (SABESP), Rodovia Anchieta, km 26,5, 09781-350 São Bernardo do Campo, SP, Brasil.

2. Departamento de Ecologia Geral, Instituto de Biociências, Universidade de São Paulo, Caixa Postal 11461, 05422-970 São Paulo, SP, Brasil.

3. Autor para correspondência: delitti@ib.usp.br quando se relaciona sua variação ao longo do tempo. Apesar desta relevância, trata-se de um dos aspectos menos conhecidos dos ecossistemas, especialmente os florestais, tendo em vista dificuldades na obtenção de dados de campo. Atualmente, as estimativas de biomassa tornaram-se ainda mais urgentes devido à sua contribuição aos estudos de mudanças globais, já que constitui um parâmetro indispensável para estimativas de alterações de reservatórios de carbono.

Nas regiões tropicais, a escassez de dados é ainda maior, havendo uma estimativa de Brown et al. (1989) de que as áreas onde a biomassa havia sido determinada diretamente era inferior a 30 ha. No Brasil, são igualmente escassos os trabalhos científicos sobre este tema, podendo ser referidos os de Delitti \& Meguro (1984) e Delitti (1998) sobre cerrados, os de Klinge et al. (1975), McWillian et al. (1993) e Higushi et al. (1994) para florestas amazônicas, além de um estudo teórico sobre a biomassa de florestas atlânticas (Delitti \& Moreira-Burger, dados não publicados). 
No estado de São Paulo, cuja cobertura vegetal original foi reduzida em mais de $90 \%$ (CONSEMA 1985), os ecossistemas florestais remanescentes são restritos a pequenas áreas isoladas, algumas porções de matas ciliares e uma área maior e mais contínua e preservada de florestas atlânticas na Serra do Mar. As matas ciliares são especialmente importantes devido às funções ecológicas que desempenham, como a de reserva de biodiversidade, estabilização de margens de cursos d'água, filtro de sedimentos e de nutrientes e influência sobre ecossistemas aquáticos, entre outras, que lhes confere um papel destacado na estruturação das paisagens (Lima 1989, Barling \& Moore 1994).

A estimativa direta da biomassa de florestas é dificultada pelas dimensões das árvores, tornando-se trabalhosa, cara e dependente de tempo e recursos humanos adequados. Além disso, a legislação ambiental vigente visa proteger os ecossistemas, dificultando a aplicação de métodos destrutivos. Métodos indiretos foram desenvolvidos por vários autores, baseados nas relações alométricas existentes entre o peso das árvores e suas dimensões lineares. Whittaker et al. (1974) e Golley et al. (1978), entre outros, desenvolveram modelos para estimativa de biomassa a partir de diâmetro e altura das árvores, ou através da associação dessas variáveis. Porém, a quase inexistência de dados primários de campo dificulta a verificação da adequação dos modelos (Egunjobi 1976), que podem variar em função da arquitetura das florestas e das densidades das madeiras presentes.

Vários trabalhos enfocaram diferentes aspectos das matas ciliares (Barbosa 1989), mas não existe nenhuma informação sobre a biomassa neste tipo de ecossistema no estado de São Paulo. Assim, o objetivo deste trabalho foi determinar diretamente a biomassa de um trecho de um desses ecossistemas e, a partir dos resultados de campo, desenvolver modelos preditivos e verificar quais os mais adequados, visando à sua aplicação a outras regiões.

\section{Material e métodos}

Área de estudo - O trabalho foi realizado num fragmento de mata ciliar do rio Mogi-Guaçu, no município de Itapira - SP, situado na área de influência do reservatório da "Usina Hidrelétrica de MogiGuaçu" $\left(22^{\circ} 21^{\prime} \mathrm{S}\right.$ e $\left.46^{\circ} 51^{\prime} \mathrm{W}\right)$. A mata estava destinada ao desmatamento, de acordo com o programa de monitoramento da qualidade da água, proposto no estudo ambiental para a construção da usina (CESP \& ENGECORPS 1993), de modo que os métodos destrutivos puderam ser aplicados. Tratava-se de um trecho remanescente de mata mesófila semidecídua ciliar (LeitãoFilho et al. 1994), caracterizado por vegetação esparsa, cujo estrato arbóreo apresentava uma densidade de 4120 indivíduos por hectare, apresentando as seguintes espécies: Sebastiania serrata (Baill.) M. Arg., Croton urucurana Baill., Nectandra megapotamica (Spreng.) Mez, Miconia aff. theaezans Cogn., Guarea macrophylla Vahl., G. guidonia (L.) Sleumer, Inga uruguensis Hook. \& Arn., Eugenia florida DC., Eugenia repanda O. Berg, Palicourea crocea (Sw.) R. \& S., Psychotria carthagenensis Jacq. e Picramnia sellowi Planchon. O dossel atingia uma altura máxima de $15 \mathrm{~m}$ e o diâmetro médio das árvores era de $9,5 \mathrm{~cm}$. O estrato herbáceo era pouco desenvolvido e as lianas abundantes. O solo era coberto por serapilheira e placas de sedimentos trazidos por inundações periódicas.

Métodos - O levantamento de campo foi realizado pelo método destrutivo, em 12 parcelas de $5 \times 5 \mathrm{~m}$, de onde foi retirada a serapilheira de $3 \mathrm{~m}^{2}$. O estrato herbáceo, composto de ervas e arbustos com altura inferior a $1,5 \mathrm{~m}$, foi também amostrado em uma subparcela de $3 \mathrm{~m}^{2}$ dentro de cada parcela, sendo cortado ao nível do solo. Em sete dessas parcelas, todas as árvores foram cortadas com moto-serra ao nível do solo. De cada árvore, foram determinados o diâmetro e a altura. A fim de ampliar o espectro de variação de alturas e diâmetros da comunidade, foram coletados outros indivíduos aleatoriamente escolhidos dentro das demais parcelas, num total de 92 árvores amostradas. As lianas foram coletadas em uma subparcela de $3 \mathrm{~m}^{2}$ dentro de cada parcela em que se coletou material arbóreo. O dimensionamento da amostragem visou obter representatividade com o menor impacto possível. As folhas do estrato herbáceo, das lianas e das árvores foram separadas manualmente do material lenhoso. $\mathrm{O}$ peso fresco de cada compartimento foi determinado com dinamômetro. Uma sub-amostra de cada fração dos componentes pesados a fresco foi levada ao laboratório e seca em estufa a $80^{\circ} \mathrm{C}$, até peso constante, a fim de se determinar a quantidade de água presente e a relação entre peso fresco e peso seco de todos os componentes. Para o desenvolvimento dos modelos, os dados do estrato arbóreo foram submetidos às análises de regressão simples e múltipla do programa EXCEL (versão 5.0), nas quais altura (m) e perímetro $(\mathrm{cm})$ foram usados como variáveis independentes.

\section{Resultados e Discussão}

A fitomassa total média estimada para essa mata ciliar a partir das parcelas amostradas foi de 133,3 t.ha ${ }^{-1}$ (tabela 1), valor muito próximo ao estimado para uma mata ciliar subtropical úmida

Tabela 1. Peso seco médio (t/ha) e desvio padrão (DP) de folhas, lenho e total dos estratos arbóreo e herbáceo e das lianas, da mata ciliar do rio Mogi-Guaçu, Itapira -SP.

\begin{tabular}{|c|c|c|c|c|c|c|}
\hline \multirow[t]{2}{*}{ Compartimento } & \multicolumn{2}{|c|}{ Folhas } & \multicolumn{2}{|c|}{ Lenho } & \multicolumn{2}{|c|}{ Total } \\
\hline & Média & $\overline{\mathrm{DP}}$ & Média & DP & Média & DP \\
\hline Arbóreo & 3,7 & 2,2 & 114,3 & 104,4 & 117,9 & 106,2 \\
\hline Herbáceo & 0,1 & 0,04 & 0,2 & 0,1 & 0,3 & 0,2 \\
\hline Lianas & 3,5 & 3,3 & 11,6 & 11,4 & 15,1 & 14,4 \\
\hline Total & 7,2 & 一 & 126,1 & - & 133,3 & - \\
\hline
\end{tabular}


(119 t.ha th $^{-1}$ em Porto Rico (Scatena et al. 1993). Meguro \& Delitti (dados não publicados) encontraram valor semelhante para mata mesófila e superior para mata ciliar do rio Paraná, em Porto Primavera. O resultado encontrado é bastante inferior ao das florestas tropicais em geral. Segundo Ovington (1965), a média para florestas temperadas é de 154 t.ha ${ }^{-1}$, enquanto para florestas tropicais variam entre $300 \mathrm{a}$ 650 t.ha ${ }^{-1}$ (McWillian et al. 1993). Comparando com cerrados, formação vegetal originalmente adjacente à mata ciliar, verifica-se que esta apresenta fitomassa muito superior. Delitti (1998) cita levantamentos nos quais a biomassa do estrato herbáceo-subarbustivo do cerrado foi estimada entre valores de 4,8 a 7,8 t.ha ${ }^{-1}$, chegando a valores superiores a 70 t.ha ${ }^{-1}$ para elementos arbustivo-arbóreos nos cerradões. Assim, os resultados obtidos indicam que a mata estudada enquadra-se num nível intermediário entre as savanas e as florestas temperadas, com fitomassa aérea inferior à das florestas tropicais em geral. A presença e a maior fitomassa da mata ciliar na região de domínio dos cerrados está condicionada pela maior disponibilidade hídrica decorrente da proximidade do lençol freático e do rio.

$\mathrm{O}$ estrato arbóreo concentra a maior quantidade de matéria orgânica, nele estando armazenados $88 \%$ da fitomassa total (lenho + folhas), seguido distantemente pelas lianas, com 11\%. Klinge et al. (1975) encontraram menor proporção de lianas (6,3\%) para floresta pluvial, além de Jordan \& Uhl (1978) que também encontraram valor inferior ao deste trabalho $(0,3 \%)$. As lianas são, portanto, uma porção representativa da vegetação estudada. A grande proporção de folhas indica seu alto investimento no aparato fotossintético, aproveitando eficientemente a luz, abundante no entorno da mata, em especial à beira do rio; sua forma de vida permite manter a mesma quantidade de folhas que o estrato arbóreo, sem o equivalente investimento em material caulinar não produtivo. O estrato herbáceo é quantitativamente pouco significativo na mata estudada.

As folhas representaram 5\% da fitomassa, com 7,0 t.ha ${ }^{-1}$ de peso seco. O lenho representou $95 \%$ da fitomassa total, com 126,1 t.ha ${ }^{-1}$. Jordan \& Uhl (1978) encontraram $2,48 \%$ de folhas na fitomassa epigéa de mata de terra firme (AM), proporção muito próxima à encontrada por Klinge et al. (1975) para floresta pluvial $(2,5 \%)$. O estrato herbáceo e lianas apresentam a maior proporção de folhas $(23 \%$ da fitomassa de cada grupo), enquanto que, da fitomassa do estrato arbóreo, apenas 3\% referemse às folhas. Considerando o total de folhas da vegetação, vê-se que apresentam-se distribuídas principalmente entre os estratos arbóreo (51\%) e entre as lianas (48\%). Por outro lado, a fitomassa lenhosa concentra-se no estrato arbóreo ( $91 \%$ de todo lenho da vegetação), enquanto $9 \%$ correspondem às lianas.

O estrato arbóreo apresentou sempre os maiores teores de água em relação ao peso seco, enquanto que as lianas apresentaram os menores teores de água na fitomassa (tabela 2). Golley et al. (1978) verificaram que a porcentagem média de umidade na fitomassa total foi de $51,8 \%$ na estação seca, resultado semelhante ao encontrado neste trabalho (51\%), que também foi realizado no período de menor pluviosidade. Golley et al. (1978) encontraram valores que variaram de 63,2 a $64,3 \%$ para folhas e de 48,4 a $54,2 \%$ para lenho, resultados que também concordam com os obtidos nesta pesquisa. A serapilheira, em ambos os trabalhos, é o compartimento da mata que apresenta o menor teor de água,

Tabela 2. Valores médios e desvio padrão (DP) do teor de água, em $\%$ do peso fresco, nos diversos compartimentos da mata ciliar do rio Mogi-Guaçu, Itapira -SP.

\begin{tabular}{lcccccccc}
\hline \multirow{2}{*}{ Compartimento } & \multicolumn{2}{c}{ Folhas } & & \multicolumn{2}{c}{ Lenho } & & \multicolumn{2}{c}{ Total } \\
\cline { 2 - 3 } & Média & DP & & Média & DP & & Média & DP \\
\hline Arbóreo & 62 & 02 & & 51 & 04 & & 51 & 04 \\
Herbáceo & 53 & 16 & & 50 & 16 & & 50 & 16 \\
Lianas & 46 & 19 & & 43 & 18 & & 15 & 03 \\
\hline Serapilheira & - & - & - & - & 15 & 03 \\
\hline
\end{tabular}

variando de $15 \%$ (neste trabalho) a 20,4\% (Golley et al. 1978).

A quantidade de serapilheira acumulada sobre o solo da mata foi de 3,2 t.ha ${ }^{-1}$, valor inferior ao esperado quando comparado com os dados de Delitti (1989), para vegetação semelhante (9,5 a 12,5 t.ha $\left.{ }^{-1}\right)$. Por tratar-se de mata ciliar periodicamente inundada, pode haver perda de serapilheira para o rio, determinando uma menor quantidade armazenada sobre o solo. Determinação da equação preditiva da fitomassa - A escolha das variáveis a serem aplicadas na análise de regressão baseou-se na literatura. Whittaker \& 
Woodwell (1968) afirmam que o volume forneceu a melhor estimativa da fitomassa da vegetação estudada por eles. Jordan \& Uhl (1978) utilizam o diâmetro ao quadrado multiplicado pela altura $\left(\mathrm{d}^{2} \cdot \mathrm{h}\right)$. Siccama et al. (1994), por outro lado, afirmam que equações que utilizam altura, ao invés de diâmetro são mais precisas.

Para Higushi et al. (1994), altura e diâmetro aplicados em quatro modelos diferentes, desenvolvidos para floresta densa de terra firme na Amazônia, produzem estimativas confiáveis de biomassa. Afirmam, ainda, que a vantagem de se usar o diâmetro como única variável independente, é que essa é uma medida facilmente obtida no campo, com poucos riscos de erros não amostrais. A vantagem de se acrescentar a altura nos modelos é que permite estimar dife- rentes biomassas para árvores de diferentes estaturas, mas de diâmetros iguais.

Assim sendo, foram ajustados modelos de regressão linear simples e múltipla para os pares de variáveis relacionados na tabela 3 . A discussão sobre qual a melhor equação preditiva da fitomassa dessa mata baseou-se inicialmente nos seguintes critérios: coeficiente de determinação $\left(\mathrm{r}^{2}\right)$, erro padrão das estimativas e o nível descritivo encontrado na análise.

Das equações de regressão linear simples, as relações entre raiz cúbica do peso seco e o perímetro apresentam os maiores valores de $\mathrm{r}^{2}$, juntamente com os menores valores de erro padrão da estimativa. Equações entre peso seco e volume (ou d $\left.{ }^{2} . h\right)$, apre-

Tabela 3. Parâmetros da regressão linear simples e múltipla de Y (PS=peso seco em kg) contra X (altura (m), perímetro (cm), d².h $\left(\mathrm{cm}^{2} . \mathrm{m}\right)$ e volume $\left(\mathrm{m}^{3}\right)$ da mata ciliar do rio Mogi-Guaçu, Itapira - SP. Entre parêntesis estão os valores de erro padrão dos coeficientes a e b. $\mathrm{N}=92$.

\begin{tabular}{|c|c|c|c|c|c|}
\hline $\mathrm{Y}$ & $\mathrm{X}$ & $\mathrm{a}$ & $\mathrm{b}$ & Erro & $\mathrm{r}^{2}$ \\
\hline PS total & $d^{2} . h$ & $-5,714(2,162)$ & $0,023(0,001)$ & 19,291 & 0,959 \\
\hline PS total & volume & $-5,703(2,172)$ & $584,857(12,791)$ & 19,376 & 0,959 \\
\hline $\ln (\mathrm{PS}$ total $)$ & altura & $-1,488(0,170)$ & $0,564(0,027)$ & 0,730 & 0,829 \\
\hline $\ln (\mathrm{PS}$ total $)$ & $\ln$ (altura) & $-3,165(0,275)$ & $3,029(0,164)$ & 0,804 & 0,793 \\
\hline $\ln (\mathrm{PS}$ total $)$ & $\ln$ (perímetro) & $-3,953(0,214)$ & $1,855(0,068)$ & 0,576 & 0,893 \\
\hline $\ln (\mathrm{PS}$ total $)$ & $\ln \left(d^{2} \cdot h\right)$ & $-2,356(0,139)$ & $0,749(0,024)$ & 0,508 & 0,917 \\
\hline$\sqrt[3]{ }$ PS total & perímetro & $0,523(0,055)$ & $0,053(0,001)$ & 0,356 & 0,944 \\
\hline PS(lenho) & $d^{2} \cdot h$ & $-5,986(2,154)$ & $0,0228(0,001)$ & 19,217 & 0,958 \\
\hline PS(lenho) & volume & $-5,977(2,161)$ & $575,655(12,728)$ & 19,280 & 0,958 \\
\hline $\ln ($ Ps lenho $)$ & altura & $-1,849(0,189)$ & $0,601(0,030)$ & 0,808 & 0,817 \\
\hline $\ln$ (PS lenho) & $\ln$ (altura) & $-3,682(0,293)$ & $3,257(0,174)$ & 0,855 & 0,796 \\
\hline $\ln$ (PS lenho) & $\ln$ (perímetro) & $-4,552(0,218)$ & $2,002(0,069)$ & 0,587 & 0,904 \\
\hline $\ln$ (PS lenho) & $\ln \left(d^{2} \cdot h\right)$ & $-2,825(0,140)$ & $0,808(0,024)$ & 0,513 & 0,926 \\
\hline$\sqrt[3]{ }$ PS lenho & perímetro & $0,447(0,056)$ & $0,053(0,001)$ & 0,362 & 0,943 \\
\hline $\ln$ (PS folhas) & altura & $-2,491(0,137)$ & $0,291(0,022)$ & 0,586 & 0,667 \\
\hline$\sqrt[3]{ }$ PS folhas & perímetro & $0,488(0,026)$ & $0,010(0,001)$ & 0,165 & 0,756 \\
\hline $\ln (\mathrm{PS}$ total $)$ & $\begin{array}{l}\text { altura }+ \\
\ln (\text { perímetro) }\end{array}$ & $-3,350(0,179)$ & $\begin{array}{l}0,245(0,030) \\
1,204(0,095)\end{array}$ & 0,439 & 0,939 \\
\hline $\ln$ (PS lenho) & $\begin{array}{l}\text { altura }+ \\
\ln (\text { perímetro })\end{array}$ & $-3,965(0,189)$ & $\begin{array}{r}0,238(0,032) \\
1,369(0,10)\end{array}$ & 0,462 & 0,941 \\
\hline
\end{tabular}

Todas as equações são significativas ao nível de $\mathrm{p}<0,01$. 
sentam também alto valor de $\mathrm{r}^{2}$, porém erro padrão pouco maior.

As equações de regressão linear múltiplas para a estimativa da fitomassa total ou do lenho apresentam alto coeficiente de determinação e erro padrão inferior às simples, porém têm a vantagem de poder diferenciar a fitomassa de indivíduos de igual perímetro com alturas distintas.

Além disso, as equações ajustadas para a previsão da fitomassa foram testadas para cada parcela, tendo como X o perímetro, altura ou $\mathrm{d}^{2}$.h. Na tabe- la 4, são apresentados os valores estimados e a variação encontrada, isto é, o grau de afastamento da fitomassa estimada em relação à obtida pelo método destrutivo, em porcentagem. A análise dessa variação indicou que a relação entre o perímetro e a raiz cúbica do peso seco gera melhor estimativa da fitomassa. Apesar de $\mathrm{d}^{2}$.h apresentar pequena variação na média geral, diferiu muito para algumas parcelas, indicando que o modelo é mais adequado para um número maior de árvores amostradas. Quanto aos modelos de múltipla regressão testa-

Tabela 4. Valores de fitomassa (Peso Seco (PS) em kg) estimados através da aplicação dos dados básicos de dimensões das árvores encontrados nas parcelas $\left(25 \mathrm{~m}^{2}\right)$ nas equações obtidas pela análise de regressão e sua variação (\%) em relação ao valor obtido por método destrutivo.

\begin{tabular}{|c|c|c|c|c|c|c|c|c|c|c|}
\hline \multirow{2}{*}{$\begin{array}{l}\text { Modelos } \\
\text { preditivos }\end{array}$} & & \multicolumn{8}{|c|}{ Parcelas $\left(25 \mathrm{~m}^{2}\right)$} & \multirow{2}{*}{$\begin{array}{l}\text { Erro } \\
\text { padrão }\end{array}$} \\
\hline & & 1 & 2 & 3 & 4 & 5 & 6 & 7 & Média & \\
\hline $\mathrm{d}^{2} . \mathrm{h} \times$ PS total & $\begin{array}{c}\text { Fitomassa } \\
\% \text { de variação }\end{array}$ & $\begin{array}{r}12,8 \\
-71,8\end{array}$ & $\begin{array}{r}468,1 \\
17,5\end{array}$ & $\begin{array}{l}700,8 \\
-12,1\end{array}$ & $\begin{array}{l}172,3 \\
-22,1\end{array}$ & $\begin{array}{r}45,0 \\
3,9\end{array}$ & $\begin{array}{r}168,9 \\
5,5\end{array}$ & $\begin{array}{r}519,2 \\
30,3\end{array}$ & $\begin{array}{r}298,2 \\
1,1\end{array}$ & 99,8 \\
\hline altura $\times \ln (\mathrm{PS}$ total $)$ & $\begin{array}{c}\text { Fitomassa } \\
\% \text { de variação }\end{array}$ & $\begin{array}{r}14,7 \\
-67,5\end{array}$ & $\begin{array}{l}271,9 \\
-31,8\end{array}$ & $\begin{array}{r}209,3 \\
-73,8\end{array}$ & $\begin{array}{r}271,9 \\
23,0\end{array}$ & $\begin{array}{r}41,2 \\
-4,9\end{array}$ & $\begin{array}{l}137,5 \\
-14,1\end{array}$ & $\begin{array}{r}474,8 \\
19,1\end{array}$ & $\begin{array}{r}203,0 \\
-31,2\end{array}$ & 59,6 \\
\hline $\ln ($ altura $) \times \ln ($ PS total $)$ & $\begin{array}{c}\text { Fitomassa } \\
\% \text { de variação }\end{array}$ & $\begin{array}{r}18,7 \\
-58,7\end{array}$ & $\begin{array}{l}138,2 \\
-65,3\end{array}$ & $\begin{array}{l}165,4 \\
-79,3\end{array}$ & $\begin{array}{r}225,6 \\
2,0\end{array}$ & $\begin{array}{l}55,9 \\
29,1\end{array}$ & $\begin{array}{l}120,4 \\
-24,8\end{array}$ & $\begin{array}{r}303,6 \\
-23,8\end{array}$ & $\begin{array}{l}146,8 \\
-50,2\end{array}$ & 36,7 \\
\hline $\ln$ (perímetro) $x \ln (\mathrm{PS}$ total $)$ & $\begin{array}{c}\text { Fitomassa } \\
\text { \% de variação }\end{array}$ & $\begin{array}{r}48,4 \\
6,8\end{array}$ & $\begin{array}{r}228,9 \\
-42,6\end{array}$ & $\begin{array}{r}315,8 \\
-60,4\end{array}$ & $\begin{array}{l}182,4 \\
-17,5\end{array}$ & $\begin{array}{l}58,4 \\
34,8\end{array}$ & $\begin{array}{l}103,7 \\
-35,2\end{array}$ & $\begin{array}{r}250,2 \\
-37,2\end{array}$ & $\begin{array}{l}169,7 \\
-42,5\end{array}$ & 38,7 \\
\hline $\ln \left(\mathrm{d}^{2} \cdot h\right) \times \ln (\mathrm{PS}$ total $)$ & $\begin{array}{c}\text { Fitomassa } \\
\% \text { de variação }\end{array}$ & $\begin{array}{r}39,2 \\
-13,6\end{array}$ & $\begin{array}{r}223,2 \\
-44,0\end{array}$ & $\begin{array}{r}288,0 \\
-63,9\end{array}$ & $\begin{array}{l}198,9 \\
-10,0\end{array}$ & $\begin{array}{l}59,0 \\
36,1\end{array}$ & $\begin{array}{l}116,3 \\
-27,4\end{array}$ & $\begin{array}{r}288,3 \\
-27,7\end{array}$ & $\begin{array}{l}173,3 \\
-41,2\end{array}$ & 39,0 \\
\hline perímetro $x \sqrt[3]{ }$ PS total & $\begin{array}{c}\text { Fitomassa } \\
\% \text { de variação }\end{array}$ & $\begin{array}{r}46,6 \\
2,7\end{array}$ & $\begin{array}{r}420,8 \\
5,6\end{array}$ & $\begin{array}{r}870,5 \\
9,2\end{array}$ & $\begin{array}{r}212,8 \\
-3,7\end{array}$ & $\begin{array}{l}54,9 \\
26,8\end{array}$ & $\begin{array}{l}131,2 \\
-18,1\end{array}$ & $\begin{array}{r}346,6 \\
-13,1\end{array}$ & $\begin{array}{r}297,6 \\
0,9\end{array}$ & 109,4 \\
\hline altura $+\ln ($ perímetro $) x \ln (\mathrm{PS}$ total $)$ & $\begin{array}{c}\text { Fitomassa } \\
\% \text { de variação }\end{array}$ & $\begin{array}{r}30,4 \\
-32,9\end{array}$ & $\begin{array}{l}274,5 \\
-31,1\end{array}$ & $\begin{array}{r}317,4 \\
-60,2\end{array}$ & $\begin{array}{r}228,7 \\
3,4\end{array}$ & $\begin{array}{l}52,1 \\
20,3\end{array}$ & $\begin{array}{l}134,6 \\
-15,9\end{array}$ & $\begin{array}{r}380,6 \\
-4,5\end{array}$ & $\begin{array}{r}202,6 \\
-31,3\end{array}$ & 50,6 \\
\hline $\mathrm{d}^{2} . \mathrm{h} \times$ PS lenho & $\begin{array}{c}\text { Fitomassa } \\
\% \text { de variação }\end{array}$ & $\begin{array}{r}11,1 \\
-73,9\end{array}$ & $\begin{array}{r}465,9 \\
18,8\end{array}$ & $\begin{array}{l}696,8 \\
-12,9\end{array}$ & $\begin{array}{l}165,5 \\
-21,6\end{array}$ & $\begin{array}{l}43,7 \\
16,6\end{array}$ & $\begin{array}{r}167,3 \\
8,9\end{array}$ & $\begin{array}{r}517,3 \\
35,1\end{array}$ & $\begin{array}{r}295,4 \\
3,4\end{array}$ & 99,6 \\
\hline Altura $x \ln (\mathrm{PS}$ lenho $)$ & $\begin{array}{c}\text { Fitomassa } \\
\% \text { de variação }\end{array}$ & $\begin{array}{r}12,3 \\
-71,1\end{array}$ & $\begin{array}{l}287,3 \\
-26,7\end{array}$ & $\begin{array}{r}207,0 \\
-74,1\end{array}$ & $\begin{array}{r}264,8 \\
25,5\end{array}$ & $\begin{array}{l}36,6 \\
-2,3\end{array}$ & $\begin{array}{l}134,2 \\
-12,7\end{array}$ & $\begin{array}{r}488,7 \\
27,6\end{array}$ & $\begin{array}{r}204,4 \\
-28,5\end{array}$ & 62,0 \\
\hline $\ln$ (altura) x $\ln (\mathrm{PS}$ lenho $)$ & $\begin{array}{c}\text { Fitomassa } \\
\% \text { de variação }\end{array}$ & $\begin{array}{r}16,2 \\
-62,0\end{array}$ & $\begin{array}{l}140,2 \\
-64,2\end{array}$ & $\begin{array}{r}159,3 \\
-80,1\end{array}$ & $\begin{array}{r}216,5 \\
2,6\end{array}$ & $\begin{array}{l}51,0 \\
36,2\end{array}$ & $\begin{array}{l}117,4 \\
-23,6\end{array}$ & $\begin{array}{l}306,6 \\
-19,9\end{array}$ & $\begin{array}{r}143,9 \\
-49,6\end{array}$ & 37,0 \\
\hline $\ln ($ perímetro $) \times \ln (\mathrm{PS}$ lenho $)$ & $\begin{array}{c}\text { Fitomassa } \\
\% \text { de variação }\end{array}$ & $\begin{array}{r}44,3 \\
3,7\end{array}$ & $\begin{array}{r}241,0 \\
-38,6\end{array}$ & $\begin{array}{r}349,8 \\
-56,3\end{array}$ & $\begin{array}{l}173,8 \\
-17,6\end{array}$ & $\begin{array}{l}53,6 \\
43,2\end{array}$ & $\begin{array}{l}101,7 \\
-33,8\end{array}$ & $\begin{array}{r}252,0 \\
-34,2\end{array}$ & $\begin{array}{l}173,7 \\
-39,2\end{array}$ & 43,1 \\
\hline $\ln \left(\mathrm{d}^{2} \cdot h\right) \times \ln (\mathrm{PS}$ lenho $)$ & $\begin{array}{c}\text { Fitomassa } \\
\% \text { de variação }\end{array}$ & $\begin{array}{r}35,5 \\
-16,8\end{array}$ & $\begin{array}{r}235,7 \\
-39,9\end{array}$ & $\begin{array}{r}313,2 \\
-60,9\end{array}$ & $\begin{array}{r}191,7 \\
-9,2\end{array}$ & $\begin{array}{l}54,2 \\
44,6\end{array}$ & $\begin{array}{l}115,1 \\
-25,1\end{array}$ & $\begin{array}{l}293,5 \\
-23,3\end{array}$ & $\begin{array}{l}177,0 \\
-38,1\end{array}$ & 42,2 \\
\hline Perímetro $x \sqrt[3]{ }$ PS lenho & $\begin{array}{c}\text { Fitomassa } \\
\text { \% de variação }\end{array}$ & $\begin{array}{l}41,9 \\
-1,8\end{array}$ & $\begin{array}{r}402,2 \\
2,6\end{array}$ & $\begin{array}{r}843,9 \\
5,5\end{array}$ & $\begin{array}{r}195,6 \\
-7,3\end{array}$ & $\begin{array}{l}49,6 \\
32,5\end{array}$ & $\begin{array}{l}122,4 \\
-20,4\end{array}$ & $\begin{array}{l}326,4 \\
-14,8\end{array}$ & $\begin{array}{r}283,1 \\
-0,9\end{array}$ & 106,5 \\
\hline Altura $+\ln$ (perímetro) $x \ln (\mathrm{PS}$ lenho) & $\begin{array}{c}\text { Fitomassa } \\
\% \text { de variação }\end{array}$ & $\begin{array}{r}28,2 \\
-33,9\end{array}$ & $\begin{array}{l}287,9 \\
-26,6\end{array}$ & $\begin{array}{r}348,5 \\
-56,4\end{array}$ & $\begin{array}{r}217,8 \\
3,2\end{array}$ & $\begin{array}{l}47,8 \\
27,6\end{array}$ & $\begin{array}{l}131,4 \\
-14,5\end{array}$ & $\begin{array}{r}378,3 \\
-1,2\end{array}$ & $\begin{array}{r}205,7 \\
-28,0\end{array}$ & 53,2 \\
\hline altura $x \ln (\mathrm{PS}$ folhas $)$ & $\begin{array}{c}\text { Fitomassa } \\
\% \text { de variação }\end{array}$ & $\begin{array}{r}1,5 \\
-41,7\end{array}$ & $\begin{array}{l}5,67 \\
-9,5\end{array}$ & $\begin{array}{r}7,59 \\
-56,5\end{array}$ & $\begin{array}{r}11,0 \\
9,5\end{array}$ & $\begin{array}{r}2,6 \\
-55,9\end{array}$ & $\begin{array}{r}4,6 \\
-30,2\end{array}$ & $\begin{array}{r}10,4 \\
-33,3\end{array}$ & $\begin{array}{r}6,2 \\
-32,5\end{array}$ & 1,4 \\
\hline Perímetro $x \sqrt[3]{ }$ PS folhas & $\begin{array}{c}\text { Fitomassa } \\
\% \text { de variação }\end{array}$ & $\begin{array}{r}2,5 \\
-7,2\end{array}$ & $\begin{array}{l}8,52 \\
36,1\end{array}$ & $\begin{array}{l}14,18 \\
-18,8\end{array}$ & $\begin{array}{r}9,4 \\
-6,7\end{array}$ & $\begin{array}{r}2,6 \\
-55,7\end{array}$ & $\begin{array}{r}4,1 \\
-38,4\end{array}$ & $\begin{array}{r}8,6 \\
-44,9\end{array}$ & $\begin{array}{r}7,1 \\
-22,6\end{array}$ & 1,6 \\
\hline
\end{tabular}


dos, verificou-se também uma grande variação (subestimam a fitomassa em cerca de 30\%).

A partir dessas considerações, pode-se concluir que as relações mais adequadas para a previsão da fitomassa (peso seco) total, lenhosa e foliar da mata estudada sejam, respectivamente: PS total $=[0,523$ $+0,053$ perímetro $]^{3}$, PS lenho $=[0,447+0,053$ perímetro $]^{3}$, PS folhas $=[0,488+0,010 \text { perímetro }]^{3}$.

Portanto, o melhor modelo que prediz a fitomassa neste estudo é uma relação cúbica entre a variável dependente e a independente, indicando que o peso das árvores está diretamente relacionado ao seu volume. Deve-se ressaltar que, embora o modelo indicado tenha sido o melhor para as folhas, o mesmo subestima a fitomassa foliar em cerca de $20 \%$. As demais equações, no entanto, não devem ser desprezadas, uma vez que são significativas e apresentam altos índices de determinação, principais critérios utilizados pela maioria dos autores. $\mathrm{O}$ presente trabalho é mais exigente quanto aos critérios usados para a validação dos modelos.

A aplicação de equações de regressão para estimativa da fitomassa de florestas tropicais é bastante criticada devido à grande heterogeneidade desses ecossistemas. McWillian et al. (1993) lembram que parâmetros como altura, diâmetro, volume e peso seco das árvores são influenciados pelas condições do local, indicando que equações específicas devem ser aplicadas, em especial no caso de florestas heterogêneas. Uma vez que refletem as características do local, não podem ser aplicadas em ambientes com características distintas sem se antecipar uma grande margem de erro (Rochow 1974). No entanto, a inexistência de levantamentos de caráter destrutivo nos diversos tipos de mata impede que equações específicas sejam obtidas.

Outra abordagem para estimativa da fitomassa epigéa do estrato arbóreo é a utilização da relação entre o peso seco e a área basal da vegetação (Satoo 1970). Verificou-se que existe uma forte relação linear entre a fitomassa obtida pelo método destrutivo e a área basal total das parcelas deste estudo (coeficiente de correlação linear de Pearson calculado: $\mathrm{r}=0,967)$. Dessa forma, calculou-se, para a mata em estudo, a relação entre o peso seco e a unidade de área basal (tabela 5). Verifica-se que tal relação é de $0,194 \mathrm{~kg} . \mathrm{cm}^{-2}$, o que equivale a 1,94 toneladas de fitomassa por metro quadrado de área basal do estrato arbóreo. Aplicando-se essa relação para a área basal total da mata estudada $\left(52,02 \mathrm{~m}^{2} \cdot \mathrm{ha}^{-1}\right)$, encontra-se um valor de 101 t.ha ${ }^{-1}$, inferior ao obtido pelo método direto (118 t.ha ${ }^{-1}$, para o estrato arbóreo), mas da mesma ordem de grandeza. Utilizando a taxa estimada para outros trechos de mata ciliar do rio Mogi-Guaçu, estima-se que a fitomassa da mata estudada por Delitti (1989) (área basal = 86,94 $\mathrm{m}^{2} \cdot \mathrm{ha}^{-1}$ ) seja da ordem de 169 t.ha ${ }^{-1}$, enquanto para a mata descrita por Leitão Filho et al. (1994) (área basal = $28,13 \mathrm{~m}^{2} \cdot \mathrm{ha}^{-1}$ ) deve ser da ordem de $55 \mathrm{t} . \mathrm{ha}^{-1}$, valores satisfatórios considerando as diferenças entre o porte e densidade de indivíduos dessas matas. Uma vez que a informação da área basal por hectare é freqüentemente encontrada nos levantamentos fitossociológicos, esta relação permite que se estime a fitomassa de ecossistemas semelhantes por meios não destrutivos, devendo-se sempre considerar as prováveis diferenças nos métodos de amostragem empregados em cada estudo.

Tabela 5. Relações entre os valores de fitomassa $(\mathrm{kg})$ e área basal $\left(\mathrm{cm}^{2}\right)$ do estrato arbóreo observadas na mata ciliar do rio MogiGuaçu (Itapira - SP) e a biomassa estimada pelo método de Satoo (1970).

\begin{tabular}{ccccc}
\hline parcela & $\begin{array}{c}\text { área } \\
\text { basal } \\
\left(\mathrm{cm}^{2}\right)\end{array}$ & $\begin{array}{c}\text { fitomassa } \\
\text { observada } \\
(\mathrm{kg})\end{array}$ & $\begin{array}{c}\text { fitomassa/ } \\
\text { área basal } \\
\left(\mathrm{kg} . \mathrm{cm}^{-2}\right)\end{array}$ & $\begin{array}{c}\text { fitomassa } \\
\text { estimada } \\
(\mathrm{kg})\end{array}$ \\
\hline 1 & 331,8 & 45,3 & 0,14 & 64,4 \\
2 & 1803,1 & 398,0 & 0,22 & 350,1 \\
3 & 2615,2 & 795,8 & 0,30 & 507,8 \\
4 & 1302,2 & 220,7 & 0,17 & 252,9 \\
5 & 401,9 & 42,9 & 0,11 & 78,0 \\
6 & 761,9 & 160,1 & 0,21 & 147,9 \\
7 & 1886,6 & 398,6 & 0,21 & 366,3 \\
Área total & 9102,7 & 2061,4 & 0,23 & 1767,5 \\
\hline Média & 1300,4 & 294,5 & 0,194 & 52,5 \\
\hline
\end{tabular}

A fim de que haja possibilidade de melhor aplicação de modelos na prática do manejo de ecossistemas, fica evidente a necessidade de se testarem diferentes modelos e de se discutirem os métodos de amostragem, visando à maior uniformidade na obtenção e interpretação dos dados. Dentro deste contexto, espera-se que as informações obtidas neste trabalho contribuam para o fornecimento de subsídios para a elaboração de projetos que visem à recuperação e manutenção de ecossistemas tão peculiares e importantes como as matas ciliares. 
Agradecimentos - Os autores agradecem à FAPESP (processo 94/ 2722), à CESP, por ceder a área para realização do trabalho e à Seção de Ecologia do Instituto de Botânica de São Paulo, pelo apoio logístico. Agradecemos a valiosa colaboração dos Drs. Sérgio Tadeu Meirelles e Pérsio de Souza Santos Filho, pelo apoio na análise estatística. A coleta dos dados foi especialmente favorecida pelo apoio do Paulo César Fernandes e do Ms. Marco Antonio Batalha.

\section{Referências bibliográficas}

BARBOSA, L.M. 1989. Estudos interdisciplinares do Instituto de Botânica em Mogi-Guaçú. In Simpósio sobre mata ciliar (L.M. Barbosa, coord.). Fundação Cargill, Campinas, p.171-191.

BARLING, R.D. \& MOORE, I.D. 1994. Role of buffer strips in management of waterway pollution: a review. Environmental Management 18:543-558.

BROWN, S., GILLESPIE, A.J.R. \& LUGO, A.E. 1989. Biomass estimation methods for tropical forests with applications to forest inventory data. Forest Science 35:881-902.

CESP (COMPANHIA ENERGÉTICA DE SÃO PAULO) \& ENGECORPS. 1993. Aproveitamento múltiplo do Rio MogiGuaçu. PCH-Mogi-Guaçu. Consolidação do Projeto Básico. Estudo Ambiental. CESP, São Paulo.

CONSEMA (Conselho Estadual do Meio Ambiente). 1985. Áreas naturais do estado de São Paulo. CONSEMA, São Paulo.

DELITTI, W.B.C. 1989. Ciclagem de nutrientes em matas ciliares. In Simpósio sobre mata ciliar (L.M. Barbosa, coord.). Fundação Cargill, Campinas, p.25-42.

DELITTI, W.B.C. 1998. Ciclagem de nutrientes em cerrados. In Anais do Seminário Regional de Ecologia, 8, UFSCar, São Carlos, p.1031-1046.

DELITTI, W.B.C. \& MEGURO, M. 1984. Biomassa e mineralomassa do campo cerrado de Mogi-Guaçu, SP. Ciência e Cultura 36 supl.:612.

EGUNJOBI, J.K. 1976. An evaluation of five methods for estimating biomass of an even-aged plantation of Pinus caribaea L. Oecologia Plantarum 11:109-116.

GOLLEY, F.B., McGINNIS, J.T., CLEMENTS, R.G., CHILD, G.I. \& DUEVER, M.J. 1978. Ciclagem de minerais em um ecossistema de floresta tropical úmida. EDUSP, São Paulo.

HIGUSHI, N., SANTOS, J.M., IMANAGA, M. \& YOSHIDA, S. 1994. Aboveground biomass estimate for Amazonian dense tropical moist forests. The Memoirs of the Faculty of Agriculture Kagoshiwa University 30:43-45.
JORDAN, C.F. \& UHL, C. 1978. Biomass of a "tierra firme" forest of the Amazon Basin. Oecologia Plantarum 13:387400.

KLINGE, H., RODRIGUES, W.A., BRUNIG, E. \& FITTKAU, E.J. 1975. Biomass and structure in a Central Amazonian rain forest. In Ecological studies - tropical ecological systems (F.B. Golley \& E. Medina, eds.). Springer Verlag, New York, p.115-122.

LEITÃO-FILHO, H.F., AZEVEDO, D.B., SANTIN, D.A. \& GARDOLINSKI, P.C.F.C. 1994. Relatório das atividades desenvolvidas no projeto "Estudos da mata ciliar dos Rios Mogi-Guaçu e Peixe - UHE Mogi-Guaçu - SP. Pq. Ecológico, FUNDETE e CESP, São Paulo.

LIMA, W.P. 1989. Função hidrológica da mata ciliar. In Simpósio sobre mata ciliar (L.M. Barbosa, coord.). Fundação Cargill, Campinas, p.25-42.

McWILLIAN, A.L.C. ROBERTS, JM CABRAL, O MR, LEITÃO, M.V.B.R., COSTA, A.C.L., MAITELLI, G.T. \& ZAMPARONI, C.A.G.P. 1993. Leaf area index above-ground biomass of terra firme rain forest and adjacent clearings in Amazonia. Functional Ecology 7:310-317.

OVINGTON, J.D. 1965. Organic production, turnover and mineral cycling in woodlands. Biological Reviews 40:295-336.

ROCHOW, J.J. 1974. Estimates of above-ground biomass and primary productivity in a Missouri Forest. Journal of Ecology 62:567-577.

SATOO, T. 1970. A synthesis of studies by the harvest method. Primary production relations in temperate deciduous forest of Japan. Ecological Studies 1:55-70.

SCATENA, F.N., SILVER, W., SICCAMA, T., JOHNSON, A. \& SÁNCHEZ, M.J. 1993. Biomass and nutrient content of the Bisley Experimental Watersheds, Luquillo Experimental Forest, Puerto Rico, before and after Hurricane Hugo, 1989. Biotropica 25:15-27.

SICCAMA, T.G., HAMBURG, S.P., ARTHUR, M.A., YANAI, R.D., BORMANN, F.H. \& LIKENS, G.E. 1994. Corrections to allometric equations and plant tissue chemistry for Hubbard Brook Experimental Forest. Ecology 75:246-248.

WHITTAKER, R.H., BORMANN, F.H., LIKENS, G.E. \& SICCAMA, T.G. 1974. The Hubbard Brook ecosystem study: forest biomass and production. Ecological Monographs 44:233-252.

WHITTAKER, R.H. \& WOODWELL, G.M. 1968. Dimension and production relations of trees and shrubs in the Brookhaven Forest, New York. Journal of Ecology 56:1-25. 